\title{
The effect of hand dominance on neuromuscular monitoring at the adductor pollicis muscle
}

\author{
Ji Seon Jeong ${ }^{1}$, Kyo Sang Kim ${ }^{1}$, Hee Jong Lee ${ }^{1}$, Jae Chul Shim ${ }^{1}$, Jong Chul Lee ${ }^{1}$, and Jeoung Hyuk Lee ${ }^{2}$ \\ Department of Anesthesiology and Pain Medicine, ${ }^{1}$ Hanyang University Hospital, Seoul, ${ }^{2}$ Ilsan Hospital, Dongguk University Medical Center, \\ Goyang, Korea
}

Background: Neuromuscular blockade of the adductor pollicis muscle may be influenced by hand dominance resulting in conflicting results of several studies. The current study examined whether hand dominance could influence the measurements of neuromuscular blockade with acceleromyography at the adductor pollicis.

Methods: The acceleromyographic responses from $0.6 \mathrm{mg} / \mathrm{kg}$ of rocuronium were monitored supramaximally in both hands in 31 patients after induction of anesthesia. Onset, maximum effect, and offset of rocuronium were measured and compared in both hands. The train-of-four (TOF) ratios to 0.9 were recorded in all patients.

Results: In total, 27 patients were right-handed and 4 patients were left-handed. The mean supramaximal threshold or initial TOF ratio was not different between dominant and nondominant hands. No statistically significant differences were found between 716 paired TOF ratios in both hands. A correlation was seen between the dominant and nondominant hand (Nondominant $=0.931$-Dominant $+1.714, \mathrm{R}=0.929$ ). The analysis by the Bland-Altman plot showed an excellent agreement with a bias of $1.6 \%$ and limits of agreement of -21.2 to $24.5 \%$.

Conclusions: Dominant and nondominant hands can be used interchangeably for neuromuscular monitoring at the adductor pollicis. (Korean J Anesthesiol 2013; 65: 33-36)

Key Words: Hand dominance, Neuromuscular blockade, Neuromuscular monitoring.

\section{Introduction}

Traditionally, train-of-four (TOF) stimulation at adductor pollicis muscle has been used in research and clinical practice. The muscle is easily accessible and essential for determination of recovery of neuromuscular transmission after neuromuscular blockade $[1,2]$. The use of the dominant hand may cause increased mechanical activity of the motor units in the dominant muscles in electromyographic studies [3]. A different sensitivity in the response to vecuronium in the dominant compared to the nondominant extremity [4]. However, Michaud et al. [5] contradicted these results showing no difference in onset

Received: November 7, 2012. Revised: December 31, 2012. Accepted: January 15, 2013.

Corresponding author: Kyo Sang Kim, M.D., Ph.D., Department of Anesthesiology and Pain Medicine, Hanyang University Hospital, 17, Haengdang-dong, Sungdong-gu, Seoul 133-792, Korea. Tel: 82-2-2290-8680, Fax: 82-2-2299-8692, E-mail: kimks@hanyang.ac.kr

(c) This is an open-access article distributed under the terms of the Creative Commons Attribution Non-Commercial License (http:// creativecommons.org/licenses/by-nc/3.0/), which permits unrestricted non-commercial use, distribution, and reproduction in any medium, provided the original work is properly cited. 
time, maximum effect, single twitch, and TOF ratio between either adductor pollicis muscle using phonomyography. Despite the fact that phonomyography is a relative new method for recording neuromuscular blockade with high sensitivity and applicability at most superficial muscles, slight movements of the microphone relative to the skin during surgery and movement of the arm could lead to a significant bias [6].

The present study was aimed at investigating the influence of hand dominance on measurements of neuromuscular blockade at the adductor pollicis muscle using acceleromyography.

\section{Materials and Methods}

This clinical observation study was approved by the Hospital Ethics Committee. Written informed consent was obtained from all patients. In total, 31 patients, aged 23 to 58 years, with an American Society of Anesthesiologists physical status of I or II and undergoing elective surgery with a general anesthesia in the supine position were studied. Exclusion criteria included body weight $20 \%$ greater than ideal body weight, a pregnancy, patients with neuromuscular, hepatic, or renal diseases, and patients receiving medications known to interact with neuromuscular blockade.

No premedication was given. After arrival to the operating room, electrocardiography, non-invasive measurement of blood pressure and oxygen saturation were performed. All patients were connected to a bispectral index (BIS) monitor (Model A 2000, Aspect Medical Systems, Natick, MA, USA). Anesthesia was induced with remifentanil $0.5 \mu \mathrm{g} / \mathrm{kg} / \mathrm{min}$ injected intravenously over 2 minutes ( $\mathrm{min}$ ) followed by propofol 2.0-2.5 $\mathrm{mg} / \mathrm{kg}$ injected intravenously over 30 seconds (s). After loss of consciousness, ventilation via facemask with a fresh gas flow at 4 $\mathrm{L} / \mathrm{min}$ (50\% nitrous oxide in oxygen) was controlled manually to maintain the end-tidal $\mathrm{CO}_{2}$ at 30 to $35 \mathrm{mmHg}$. Maintenance of anesthesia was with 1.0-1.5 MAC of sevoflurane in a gas mixture of $50 \%$ nitrous oxide in oxygen to maintain a BIS between 40 and 50 and infusion doses of remifentanil $0.05-0.20 \mu \mathrm{g} / \mathrm{kg} / \mathrm{min}$ throughout surgery.

Neuromuscular function was assessed using acceleromyography of the adductor pollicis muscle (TOF-Watch $\mathrm{SX}^{\circledR}$, Organon Ltd., Dublin, Ireland). Before placing the surface electrodes, the skin overlying the ulnar nerve of the dominant and nondominant hands was cleansed with isopropyl alcohol. Two electrodes (Cleartrode ${ }^{\mathrm{TM}}$, Ref 1720-003, ConMed ${ }^{\circledR}$, Utica, NY, USA) were placed over the prepared skin on both forearms. A force transducer was fixed to the thumb. No special arm board was used and no preload was applied to the thumb during the entire study procedure.

After the loss of eyelash reflex was confirmed, neuromuscular monitoring began immediately. A $5-\mathrm{s} 50-\mathrm{Hz}$ tetanic stimulus

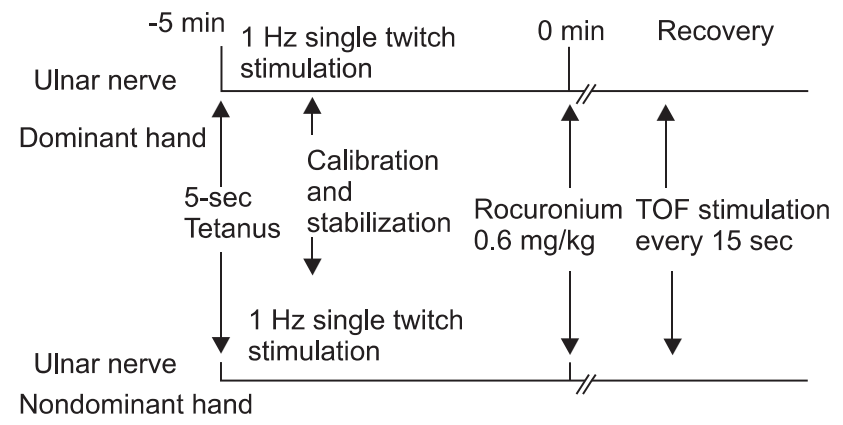

Fig. 1. Time course of the measurements of neuromuscular blockade at the adductor pollicis in both hands.

was applied over both ulnar nerves, respectively. The fingers of both arms were tightly fixed to the armboard, respectively. The calibration and supramaximal stimulation were achieved by the built-in calibration function (CAL 2) of the TOF-Watch SX ${ }^{\circledR}$, respectively [7]. Stable baseline was completed in at least $2 \mathrm{~min}$ $(<5 \%$ variation in the first twitch and TOF). After stabilization of control responses, rocuronium $(0.6 \mathrm{mg} / \mathrm{kg})$ was administered and tracheal intubation was performed at the disappearance of the TOF response. TOF stimulation $(0.2 \mathrm{~ms}$ duration, frequency $2 \mathrm{~Hz}, 2 \mathrm{~s}$ duration with supramaximal current) was repeated every $15 \mathrm{~s}$ and applied throughout maintenance of anesthesia (Fig. 1). Ventilation was adjusted to maintain end-tidal carbon dioxide between 30 and $35 \mathrm{mmHg}$. All neuromuscular data were collected on a computer and monitored throughout the study. Skin temperature on the wrist was maintained to more than $32^{\circ} \mathrm{C}$ using a wrapping cotton wool and central temperature was maintained to more than $35^{\circ} \mathrm{C}$ using a forced air warmer. The time to the onset, maximum effect, and offset of rocuronium were measured. Signal recordings were continued until the TOF ratio to 0.9. Additional doses of rocuronium were given if required. At the end of surgery, the patients received neostigmine $(50 \mu \mathrm{g} /$ $\mathrm{kg})$ and glycopyrrolate $(10 \mu \mathrm{g} / \mathrm{kg})$ if necessary.

Statistical analysis was performed using the SPSS (SPSS for Windows Release 14.0) statistical software package. The sample size $(\mathrm{n}=28)$ was determined based on the following criteria: a significance level of $5 \%$ and a power of $80 \%$ with an estimated difference of 1 minute at a standard deviation of 0.25 minutes to reach a TOF ratio of $25 \%$ between both hands. In the experiment, 31 patients were decided with given $10 \%$ wastage rates. Differences in pharmacodynamic variables between TOF ratios on both hands were analyzed using paired Student's t-tests. Linear correlations between the measured parameters were analyzed using the method of least squares analysis. To compare dominant and nondominant hand, the values from each stimulation site were compared by using a Bland and Altman analysis [8]. A P value $<0.05$ was considered as statistically significant. 
Table 1. Initial Measurements

\begin{tabular}{lcc}
\hline \multicolumn{1}{c}{ Variable } & $\begin{array}{c}\text { Dominant } \\
\text { hand }\end{array}$ & $\begin{array}{c}\text { Nondominant } \\
\text { hand }\end{array}$ \\
\hline $\begin{array}{l}\text { Supramaximal stimulation }(\mathrm{mA}) \\
\quad \text { Mean } \pm \text { SD }\end{array}$ & $36.7 \pm 7.4$ & $37.6 \pm 8.3$ \\
$\quad$ Range & $27-51$ & $26-53$ \\
Initial TOF ratio (T4/T1) (\%) & & \\
$\quad$ Mean \pm SD & $97.9 \pm 3.5$ & $98.2 \pm 4.1$ \\
$\quad$ Range & $88-109$ & $89-112$ \\
\hline
\end{tabular}

TOF: train-of-four.

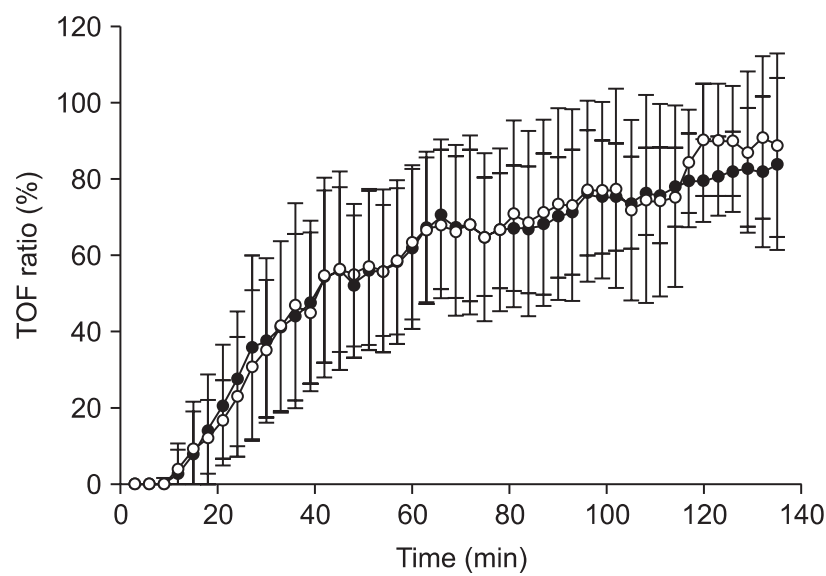

Fig. 2. Train-of-four (TOF) ratio as means (SD) of all patients for the dominant (black) and nondominant hand (white).

\section{Results}

A total of 31 patients were included in the study: 19 men and 12 women (age, $42.9 \pm 11.3$ years; weight, $71.1 \pm 12.3 \mathrm{~kg}$; height, $168.1 \pm 10.2 \mathrm{~cm}$; duration of anesthesia, $169 \pm 67$ minutes). There were 27 right-handed patients and 4 left-handed patients analyzed. There were no differences in the mean supramaximal threshold or mean initial TOF ratio between the dominant or nondominant hands, as presented in Table 1. During recovery, 716 paired TOF ratios were recorded from both hands simultaneously. No statistical differences in the TOF ratios were found during recovery in the dominant and nondominant hands of the same patient (Fig. 2). A regression line of data from the dominant and nondominant hands had an intercept (ic) of 1.714, regression coefficient (b) of 0.931 , and correlation coefficient $(R)$ of 0.929 (Fig. 3). There was a bias of $1.6 \%$ and the $95 \%$ limits of agreement between dominant versus nondominant hands were from -21.2 to $24.5 \%$ of the values using a Bland-Altman analysis (Fig. 4).

\section{Discussion}

We found pharmacodynamic values of the dominant hand to

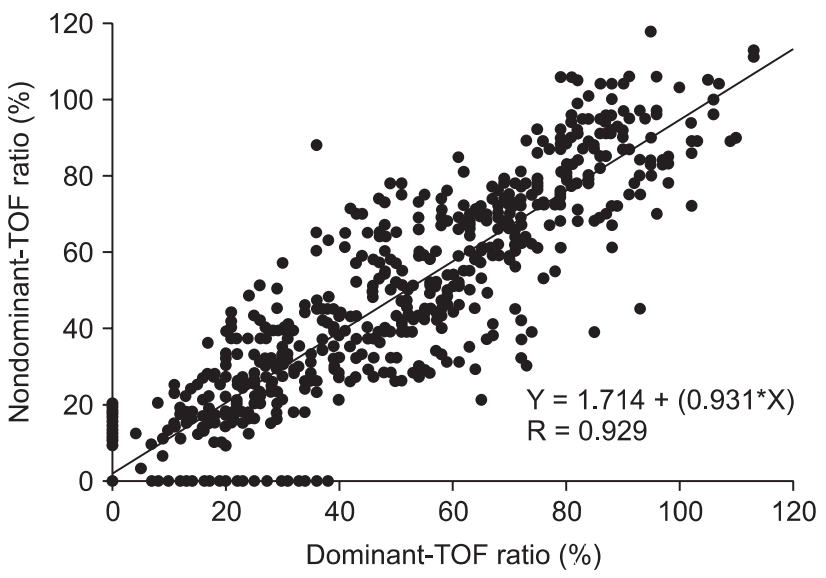

Fig. 3. Correlation in 716 paired TOF ratios between dominant and nondominant hands.

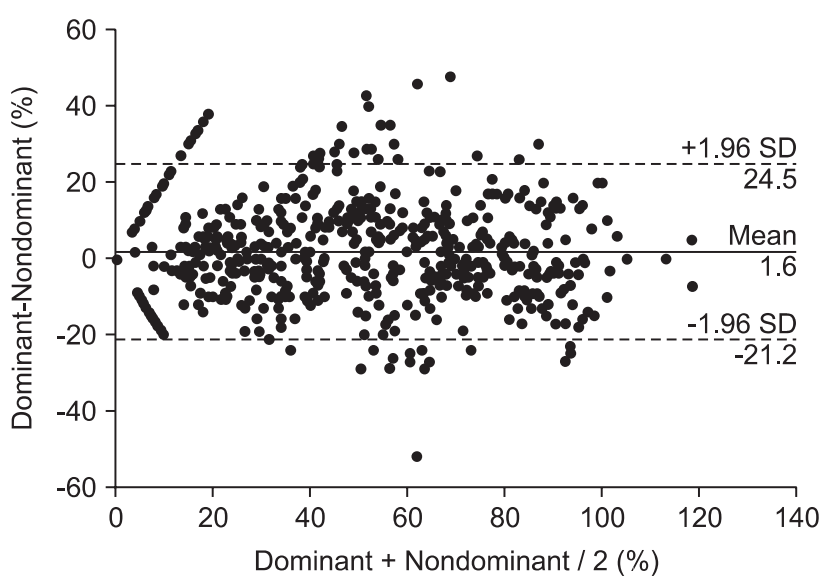

Fig. 4. Bland-Altman plot of 716 paired TOF ratios for dominant and nondominant hand.

be comparable to those obtained at the nondominant hand with minimal bias, good correlation, and no statistical differences. The neuromuscular blockade was not influenced by hand dominance.

Motor unit recruitment and firing behavior of the first dorsal interosseous muscle of dominant and nondominant hands in volunteers were compared. The presence of lower average firing rates, lower recruitment thresholds, and greater firing rate/force delay in the dominant muscles suggests an increased percentage of slow twitch fibers from electromyographic studies. These adaptations could potentially lead to a different response to neuromuscular blockade [3]. A different sensitivity between the dominant and nondominant hands was suggested by the potency ratio of vecuronium or 3-desacetylvecuronium at the adductor pollicis muscle via mechanomyography [4]. In another study using phonomyography at the adductor pollicis muscle, Michaud et al. contradicted those results showing no difference in onset time, maximum effect, time to reach $25,50,75$, and 
$90 \%$ of control twitch response, and TOF ratio of $0.5,0.7,0.8$, and 0.9 when comparing dominant and non-dominant hands [5]. Nelson et al. [9] examined specific electrical characteristics of voluntary single motor unit action potentials (amplitude, duration, phase change, and rate of rise) from the abductor pollicis brevis and the abductor digiti minimi of the hand. They found no significant differences between muscles in the dominant and non-dominant hands. Despite morphological changes of the muscle in the dominant hand, we did not find any statistical differences between the adductor pollicis muscles of either hand using acceleromyography. The individual differences were wide when using acceleromyography or mechanomyography, although there was no significant mean bias in any recovery parameter between the arms [10]. We also found in Fig. 3 and 4.

Acoustic monitoring of neuromuscular activity at the adductor pollicis muscle during anesthesia correlated closely with monitoring by electromyography, accelorography, and mechanomyography [11]. Phonomyography is a relatively new method for recording neuromuscular blockade at most superficial muscles [6], however, slight movements of the microphone could lead to a significant bias and no commercial devices are currently available. Additionally, phonomyography displayed a slower onset and a faster recovery than mechanomyography at the adductor pollicis muscle after a bolus injection of rocuronium, which was not interchangeable at submaximal levels of neuromuscular blockade [12]. But acceleromyography and mechanomyography can be used interchangeably, when both methods are normalized [13]. For these reasons, we chose to use acceleromyography as a measurement of neuromuscular blockade at the adductor pollicis muscle.

One limitation is that repeated TOF stimulation (every 15 s) during the anesthesia is not exactly same time between the dominant and non-dominant hands due to the calibration mode and fixed fingers to the armboard, respectively.

In conclusion, our results suggest that the dominant or nondominant hand may be used for neuromuscular junction blockade monitoring at the adductor pollicis muscle.

\section{References}

1. Bigland-Ritchie B, Jones DA, Woods JJ. Excitation frequency and muscle fatigue: electrical responses during human voluntary and stimulated contractions. Exp Neurol 1979; 64: 414-27.

2. Lee HJ, Kim KS, Shim JC, Yoon SW. A comparison of the accuracy of ulnar versus median nerve stimulation for neuromuscular monitoring. Korean J Anesthesiol 2011; 60: 334-8.

3. Adam A, De Luca CJ, Erim Z. Hand dominance and motor unit firing behavior. J Neurophysiol 1998; 80: 1373-82.

4. Caldwell JE, Szenohradszky J, Segredo V, Wright PM, McLoughlin C, Sharma ML, et al. The pharmacodynamics and pharmacokinetics of the metabolite 3-desacetylvecuronium (ORG 7268) and its parent compound, vecuronium, in human volunteers. J Pharmacol Exp Ther 1994; 270: 1216-22.

5. Michaud G, Trager G, Deschamps S, Hemmerling TM. Dominance of the hand does not change the phonomyographic measurement of neuromuscular block at the adductor pollicis muscle. Anesth Analg 2005; 100: 718-21.

6. Hemmerling TM, Babin D, Donati F. Phonomyography as a novel method to determine neuromuscular blockade at the laryngeal adductor muscles: comparison with the cuff pressure method. Anesthesiology 2003; 98: 359-63.

7. Kopman AF, Kumar S, Klewicka MM, Neuman GG. The staircase phenomenon: implications for monitoring of neuromuscular transmission. Anesthesiology 2001; 95: 403-7.

8. Bland JM, Altman DG. Statistical methods for assessing agreement between two methods of clinical measurement. Lancet 1986; 1: 307-10.

9. Nelson RM, Cauley T, Fink M, Lauretani C, Simonson T. Comparison of motor unit action potential characteristics and hand dominance using monopolar needle electrodes in the abductor pollicis brevis and abductor digiti minimi muscles. Electromyogr Clin Neurophysiol 2003; 43: 17-22.

10. Claudius C, Skovgaard LT, Viby-Mogensen J. Arm-to-arm variation when evaluating neuromuscular block: an analysis of the precision and the bias and agreement between arms when using mechanomyography or acceleromyography. Br J Anaesth 2010; 105: 310-7.

11. Dascalu A, Geller E, Moalem Y, Manoah M, Enav S, Rudick Z. Acoustic monitoring of intraoperative neuromuscular block. Br J Anaesth 1999; 83: 405-9.

12. Bellemare F, Couture J, Donati F, Plaud B. Temporal relation between acoustic and force responses at the adductor pollicis during nondepolarizing neuromuscular block. Anesthesiology 2000; 93: 646-52.

13. Claudius C, Skovgaard LT, Viby-Mogensen J. Is the performance of acceleromyography improved with preload and normalization? A comparison with mechanomyography. Anesthesiology 2009; 110: 1261-70. 